Research Article

\title{
Structure Design and Flow Field Analysis of a Model Test Box Used to Study Freezing Temperature Field of Seepage Stratum
}

\author{
Renliang Shan (D), Weijun Liu $\left(\mathbb{D}\right.$, Zhe Liu ${ }^{D}$, and Zhien Wang \\ College of Mechanics and Construction Engineering, China University of Mining and Technology-Beijing, Beijing 100083, China \\ Correspondence should be addressed to Weijun Liu; 1615541146@qq.com
}

Received 23 February 2021; Accepted 10 June 2021; Published 18 June 2021

Academic Editor: Robert Černý

Copyright ( 2021 Renliang Shan et al. This is an open access article distributed under the Creative Commons Attribution License, which permits unrestricted use, distribution, and reproduction in any medium, provided the original work is properly cited.

\begin{abstract}
To meet the research needs of the freezing temperature field under seepage, we investigate and design a seepage-freezing model test box, which can meet the requirements of strength, deformation, dispersed flow, simulated laminar flow, and water sealing performance. Using theoretical analysis and calculation, the pressure design index of the model box was obtained. Based on safety considerations, the model test box was designed with a pressure vessel bearing of $0.05 \mathrm{MPa}$. The structure of "sink + porous plate" was used inside the box. By flow field analysis, the porous plate can effectively reduce the influence of flow convergence to the orifice on the flow field and achieve the purpose of dispersed-water flow and laminar flow simulation. The composite structure form of "panel + frame beam" was adopted to perform the load-bearing test. Under the pressure of $0.05 \mathrm{MPa}$, the maximum deformation in the $x, y$, and $z$ directions was $<2.4 \mathrm{~mm}$, and the maximum stress was approximately $248 \mathrm{MPa}$. The model box could meet the requirements of strength and deformation. Water sealing between the upper cover plate and lower box body was achieved by arranging bolts, iron sheets, and silica gel strips. After testing the processed box, we found that the designed box can fully meet the test requirements. These research results may be used as a reference for the development and design of other seepage-freezing model test boxes.
\end{abstract}

\section{Introduction}

In subway tunnel and mine engineering, when the geological conditions are harsh or the groundwater is difficult to control, freezing technology is widely used due to its good water sealing, safety, and environmental protection [1-4]. Scholars at home and abroad have conducted various studies on freezing technology. Vasilyeva et al. [5] presented the mathematical model and the fine grid approximation for heterogeneous porous media, in which freezing pipes were considered as line source terms, successfully simulating the heat transfer problem in the process of artificial ground freezing. Zhou et al. [6] studied the influence of different factors on freezing wall overlapping time and freezing wall thickness through the double-hole orthogonal model test. Sudisman et al. [7] observed how seepage water affected the heat distribution characteristics in freezing engineering using an infrared thermal imager in the model test. In order to ensure the stability and waterproofing of soil when excavating two tunnels in a real underground station, Mauro et al. [8] put forward a numerical model to analyze the heat transfer during the whole excavation process using horizontal artificial ground freezing technology and verified the validity and correctness of the numerical model through the data. Yang and Pi [9] simulated the single tube freezing process through numerical simulation and obtained the quantitative relationship between the maximum freezing tube spacing and other factors. Tounsi et al. [10] proposed a fully coupled THM model, with consideration of the salinity effect, and the correctness of the model was proven through laboratory test results. Lai et al. [11] derived the governing differential equation for the coupling problem of the phase transition temperature field and seepage field and obtained the finite element calculation formula for the problem using the Galerkin method. Pimentel et al. [12] simulated the freezing wall forming process of a single row of pipes under high seepage velocity through large-scale physical model tests and compared and discussed the results with the 
existing closed-form solutions for AGF. Li and Xia [13] obtained an approximate analytical solution for transient frozen soil temperature distribution based on the exponential integral function. $\mathrm{Hu}$ and $\mathrm{He}[14,15]$ derived the equivalent trapezoidal algorithm for calculating the average temperature of the frozen wall of double or multiple rows of pipes based on the Bajorkin formula. In addition, many scholars have conducted various studies on the freezing temperature field using various technical means [16-19].

It can be observed that artificial freezing technology has a wide range of application prospects. The physical model test, as an efficient and quick method, is of great significance to the study of the variation law of a freezing temperature field in percolating strata. In order to ensure the validity and correctness of the model test, the properly designed seepagefreezing model test box should meet the following requirements:

(1) Strength and Deformation. A reasonable seepagefreezing model test box needs to meet the requirements of strength and deformation. If the bearing capacity of the model box is too small, many additional restrictions would be imposed on the design and conduct of the model test. There would also be cases of damage to the model test box due to excessive load during the test process.

(2) Reasonable Structure. Reasonable structure has an important impact on the model box. An unreasonable structure design would not only lead to the waste of resources but also has an important impact on the bearing capacity of the structure.

(3) Disperse Water Flow and Simulate Laminar Flow. In the simulation of groundwater seepage, the phenomenon of flow convergence to the orifice would usually occur. If the effect of the flow convergence to the orifice cannot be effectively solved, this would have an important impact on the test results.

(4) Good Capacity for Water Sealing. When carrying out the model test, it is necessary to ensure that there would be no water leakage during the test process in order to ensure the normal conduction of the test.

It can be observed that the reasonable design of the seepage-freezing model test box needs to meet the requirements of many aspects at the same time. This is the basis for the correct research of the freezing model test under the action of seepage. However, authors rarely find the literature to introduce the design method of the seepage-freezing model test box. Therefore, the present study describes the design idea and process of a seepage-freezing model test box used to study the development law of freezing temperature fields under seepage. Using the theoretical calculation and combining two different numerical simulation techniques through flow field analysis and mechanical analysis, a set of seepagefreezing model test box was designed. This met the requirements of strength, deformation, simulated laminar flow, and water sealing. The research results provide reference for the design of the seepagefreezing model test box.

\section{Design Requirements and Design Indicators}

2.1. Design Requirements. As shown in Figure 1, the design material of the model test box was steel, and the box can be divided into five main components: (1) five panels of bottom, left, right, inlet, and outlet (grey); (2) frame beam; (3) top cover slab; (4) porous plate; and (5) inlet and outlet.

In order to ensure the accuracy and safety of the model test, the following three design requirements were proposed for the seepage-freezing model test box:

(1) The box body can meet the strength and requirements

(2) Water can simulate the laminar flow when this flows through the test layer

(3) The box body has good sealing water

2.2. Pressure Design Index. Due to the limitation of the site, the internal size of the model box was preliminarily set to $1,200 \times 1,200 \times 765 \mathrm{~mm}$.

Figure 2 presents the design soil layer layout.

The bottom panel was mainly subjected to soil gravity stress and seepage water pressure. The density of the sand $\rho_{\mathrm{s}}$ was $1,400 \mathrm{~kg} / \mathrm{m}^{3}$, and the density of the clay $\rho_{\mathrm{c}}$ was $2,000 \mathrm{~kg} /$ $\mathrm{m}^{3}$ in order to obtain the dead weight stress:

$$
\sigma_{c z}=\rho_{s} \mathrm{H}_{s}+\rho_{c} \mathrm{H}_{c}=11.52 k P a,
$$

where $H_{\mathrm{s}}$ is the thickness of sand layer and $H_{\mathrm{c}}$ is the thickness of clay layer.

According to literature [20], the empirical value of the permeability coefficient of coarse sand is $0.05 \mathrm{~cm} /$ $\mathrm{s} \sim 0.01 \mathrm{~cm} / \mathrm{s}(43.2 \mathrm{~m} / \mathrm{d} \sim 8.64 \mathrm{~m} / \mathrm{d})$. Therefore, the present study took the permeability coefficient $k=20 \mathrm{~m} / \mathrm{d}$ as the designed permeability coefficient.

The designed maximum seepage velocity $v$ was $25 \mathrm{~m} / \mathrm{d}$ according to Darcy's law:

$$
v=k \frac{\Delta h}{L}
$$

where $L$ is the length of the hydraulic path.

The permeability coefficient $k=10 \mathrm{~m} / \mathrm{d}$, the seepage velocity $v=25 \mathrm{~m} / \mathrm{d}$, and the hydraulic path $L=1.2 \mathrm{~m}$ were placed into equation (2) to obtain the water pressure on the inlet surface:

$$
P_{\mathrm{i}}=P_{\mathrm{o}}+\Delta h=31 \mathrm{kPa}
$$

where $P_{\mathrm{o}}$ is the water pressure at the outlet surface; because this is connected with air, take $P_{\mathrm{o}}=1 \mathrm{kPa}$.

The maximum stress on the bottom panel can be obtained as follows: 


$$
\sigma_{z}=\sigma_{c z}+P_{i}=42.52 \mathrm{kPa}
$$

Since there is no reference standard for the freezingseepage model test box, in consideration of safety, the present study designed the seepage-freezing model test box according to the pressure vessel bearing of $0.05 \mathrm{MPa}$ and took the maximum allowable deformation of the box as its internal size of $2 \%$, that is, $2.4 \mathrm{~mm}$.

\section{Design Scheme and Effect Analysis}

\subsection{Flow Field Analysis}

3.1.1. Porous Plate Design Scheme. For the purpose of setting the porous plate, when simulating the groundwater seepage, the water can flow in and out of the model box more evenly, reducing the influence of flow convergence to the orifice on the flow field.

Porous Plate Setting Method. As shown in Figure 3, the porous plate comprises of a number of steel plates with dense holes, and this is connected to the inlet/outlet panel through an internal beam, with a cross section size of $10 \times 10 \mathrm{~mm}$. The internal beam divides the porous plate into six small porous plates. Finally, the inlet panel and outlet panel, the porous plate, and the internal beam form six independent water collecting tanks, as shown in Figure 4. After converging in the water collecting tank, the fluid evenly flows in and out of the formation through the closely spaced holes on the porous plate, thereby achieving the effect of simulating the laminar flow.

Considering the $0.63 \mathrm{~m}$ high sand layer at the middle of the model test box as the main test layer, the permeable holes were only arranged at the middle $0.63 \mathrm{~m}$ high range. The preliminary design permeable hole diameter was set as $d_{\mathrm{p}}=6 \mathrm{~mm}$ in order to prevent the porous plate from losing too much bearing capacity because the permeable hole spacing is too small and the permeable holes being too dense. The permeable hole spacing of $S \geq 60 \mathrm{~mm}$ should be no less than 10 times the permeable hole diameter, that is, $S \geq 60 \mathrm{~mm}$. Taking the permeable hole row spacing of $S_{\mathrm{r}}=70 \mathrm{~mm}$, the maximum number of rows of permeable holes can be arranged as follows:

$$
m \leq[630 \div 70-1]=8 \text {. }
$$

Taking $m=8$, a total of eight rows of water holes are arranged. In the same manner, taking the permeable hole column spacing of $S_{\mathrm{c}}=70 \mathrm{~mm}$, the maximum number of columns of permeable holes can be arranged as follows:

$$
n \leq[(1200-2 \times 10) \div 70-1]=15 .
$$

Taking $n=15,15$ columns of permeable holes are arranged. Due to the small size difference of the six porous plates, the same number of permeable holes was arranged in each porous plate, and each porous plate was arranged with four rows and five columns; that is, there were a total of 20 permeable holes. The specific layout location and mode of permeable hole are shown in Figure 3.
3.1.2. Verification of the Effect of the Porous Plate. In this section, numerical simulation was used as the technical means to analyze the flow field of the model with or without porous plate in order to verify whether the porous plate can reduce the influence of the flow convergence to the orifice on the flow field and make the seepage distribution of stratum water uniform.

Boundary conditions are as follows:

(1) Inlet boundary condition: $25 \mathrm{~m} / \mathrm{d}$

(2) Outlet boundary condition: free flow

(3) Other wall surfaces were set as walls

The velocity diagrams of the two groups with and without porous plates were compared when the hydraulic path length was $0.60 \mathrm{~m}, 0.90 \mathrm{~m}, 1.10 \mathrm{~m}$, and $1.19 \mathrm{~m}$, respectively. The effect of the porous plates was analyzed through the numerical simulation results, as shown in Figure 5.

As shown in Figure 5, when the hydraulic path length was $0.60 \mathrm{~m}$ and $0.90 \mathrm{~m}$, the maximum flow velocity of the nonporous plate model was not much different from that of the porous plate model, the water seepage in the stratum was uniform, and the phenomenon of flow convergence to the orifice was not obvious. When the hydraulic path length was $1.10 \mathrm{~m}$, the phenomenon of flow convergence to the orifice of the nonporous plate was obvious, and the maximum velocity of the nonporous plate model was more than twice of that of the porous plate model. This phenomenon shows that when there is no porous plate, the hydraulic path length starts from $0.90 \mathrm{~m}$, and the effect of the water convergence to the orifice on the flow field begins to significantly increase. For the model with a porous plate, the effect of the water convergence to the orifice on the flow field was not obvious, and the flow field continued to present a relatively uniform situation. When the hydraulic path length was $1.19 \mathrm{~m}$, the phenomenon of flow convergence to the orifice of the nonporous plate was more obvious, and the maximum velocity was far higher than that of the permeable plate model.

From this, the following can be concluded:

(1) The closer it is to the outlet, the more obvious the phenomenon of flow convergence to the orifice becomes

(2) The porous plate plays a very important role in simulating the laminar flow and reducing the influence of the flow convergence to the orifice on the flow field

(3) It is necessary to set a porous plate inside the model box

\subsection{Structural Design}

3.2.1. Design Process. Frame structure refers to the beam and column through the rigid connection and constitutes the structure of the load-bearing system. That is, the beam and column together constitute the framework to bear the load in the process of use. 


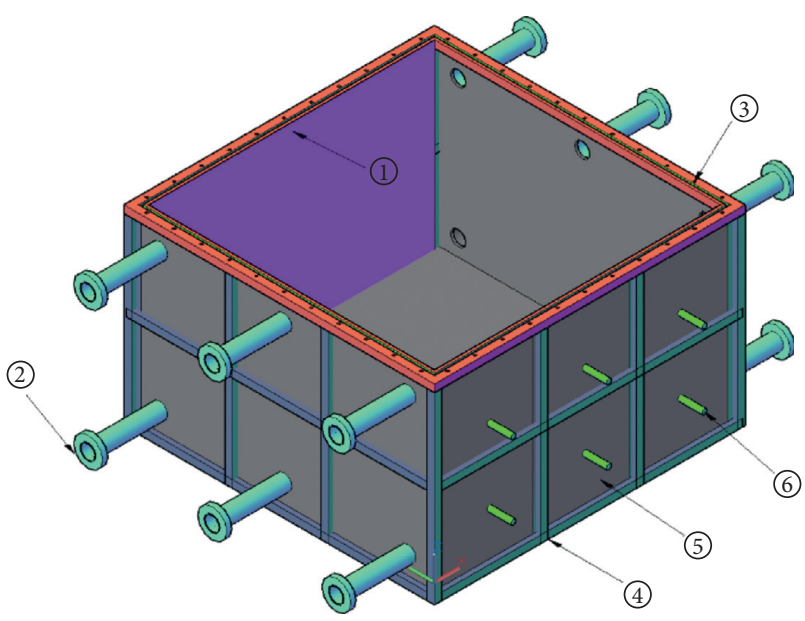

(a)

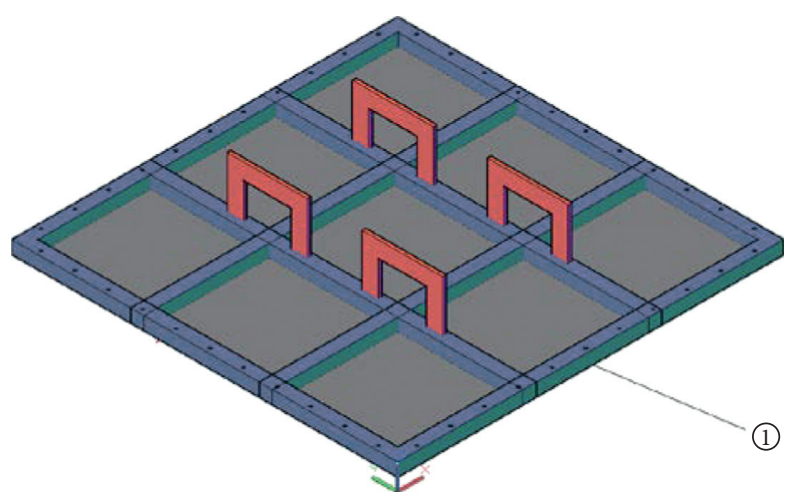

(b)

FIgURE 1: Schematic diagram for the model box: (a) schematic diagram for the lower box and (b) diagram for the upper cover.

As an excellent structural design system, this has many advantages and is widely used in construction projects as follows:

(1) The integrity of the structure is good, the strength is large, and the stiffness is high

(2) Light weight and saves on materials

(3) Flexible space separation, allowing for more flexibility to allocate space

(4) The beam and column components of the frame structure can easily be standardized, making it convenient for the purchasing of materials

Based on the advantages of the above frame structure, the present study designed the seepage-freezing model test box with reference to the frame structure design ideas in architectural engineering.

The specific design process is as follows:

(1) The structural form of "panel + frame beam" was preliminarily determined.

(2) The frame beams were combined into the overall load-bearing structure as shown in Figure 6. With the composite frame beam as the main load-bearing member, the panels are welded in the frame to form the collaborative load-bearing structure system of "frame beam + panel."

(3) With numerical simulation as the technical means, the numerical simulation calculation was carried out for a number of times, through the manner of constantly modifying the design parameters, in order to achieve the goal of meeting the requirements of the structural design.

Design parameters are as follows: panel thickness, frame beam cross section size, frame beam layout position, and frame beam layout spacing.

Design objectives are as follows: (1) the maximum allowable deformation of the box was $2 \%$ of the internal size, that is, $2.4 \mathrm{~mm}$ and (2) the maximum principal stress of the box was less than the yield strength of Q250 steel; that is, the maximum principal stress was less than $250 \mathrm{MPa}$.

3.2.2. Establishment of the Numerical Model. After making the following assumptions, the present study established the structural analysis model, as shown in Figure 7:

(1) The connection between two beams, the beam and plate, and two plates was regarded as a rigid connection

(2) The upper cover plate and lower box body were regarded as a whole

(3) The influence of the internal beam connected to the porous plate and the panel was ignored

3.2.3. Numerical Results. Figure 8 presents the distribution of the stress and displacement of the model box when the thickness of each panel is $5 \mathrm{~mm}$, the cross section size of the beam is $30 \times 30 \mathrm{~mm}$, and a pressure of $0.05 \mathrm{MPa}$ is applied.

It can be observed from Figure 8 that the maximum displacement of the box body occurs in the middle of each panel. The maximum displacement in the $x$ direction is $0.42 \mathrm{~mm}$, the maximum displacement in the $y$ direction is $0.42 \mathrm{~mm}$, and the maximum displacement in the $z$ direction is $1.9 \mathrm{~mm}$, which are all less than $2.4 \mathrm{~mm}$.

The maximum stress of the box is approximately $248 \mathrm{MPa}$, which is less than $250 \mathrm{MPa}$ (the yield strength of Q250 steel). The strength and deformation meet the design requirements of the model test box.

\subsection{Bolt Layout and Water Sealing Design}

3.3.1. Quantity Calculation of the Bolts. The total stress of all bolts is as follows:

$$
F_{\mathrm{a}}=q S=72000 \mathrm{~N}
$$

where $F_{\mathrm{a}}$ is the total stress of all bolts, $q$ is the uniform load, and $S$ is the stressed area. 


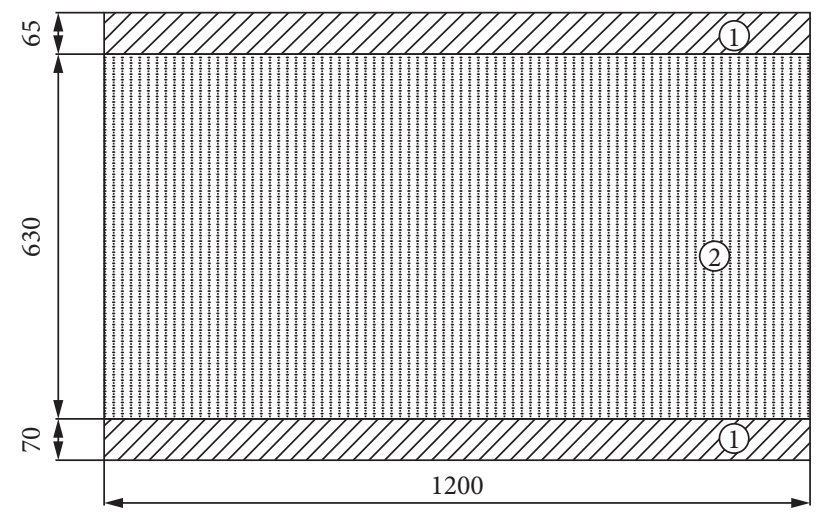

(1) Clay

(2) Sand

Figure 2: Design soil layer layout.

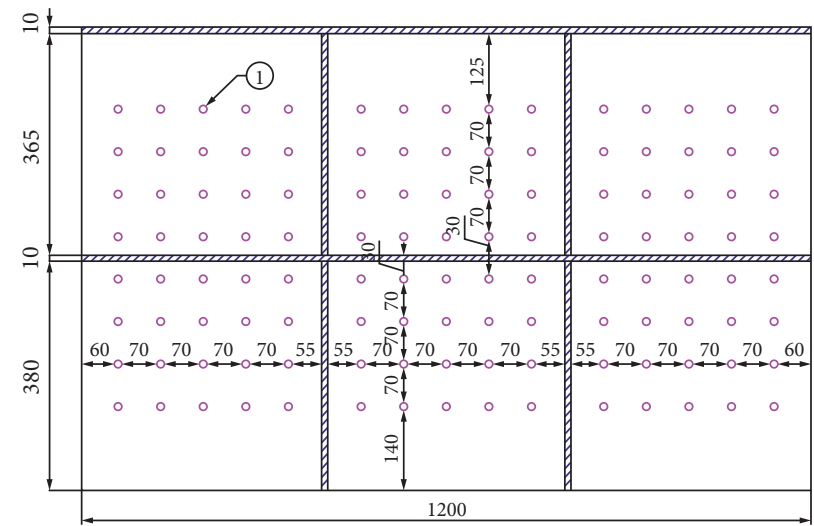

(1) Permeable hole

Figure 3: Design drawing of the porous plate.

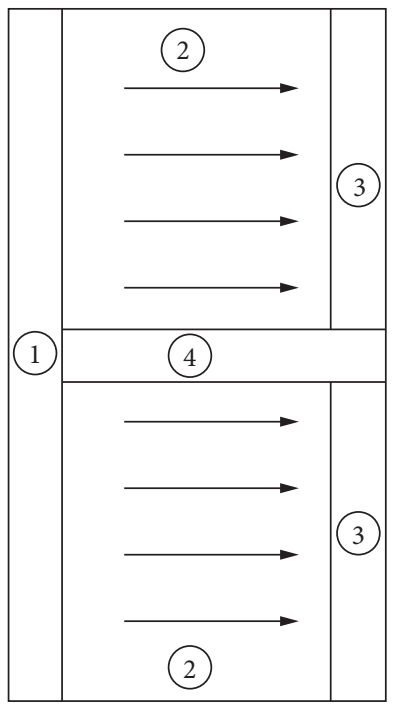

(1) Inlet panel

(2) Flow direction

(3) Porous plate

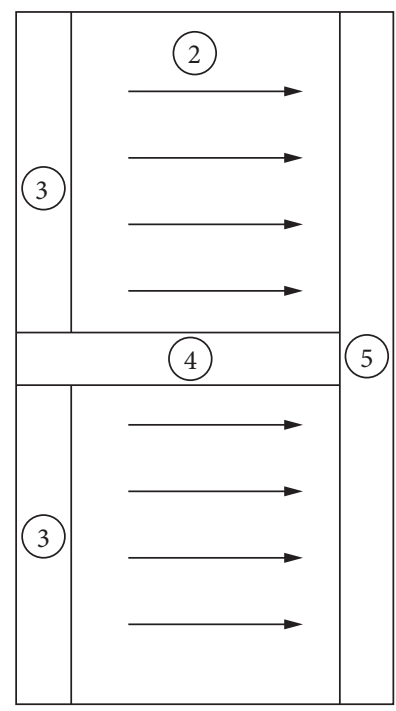

(4) Inner beam

(5) Outlet panel

Figure 4: Schematic diagram for the water collecting tank. 


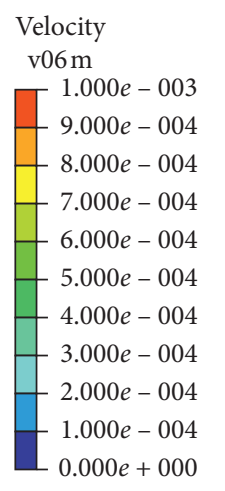

[ $\mathrm{m} \mathrm{s}^{-1}$ ]

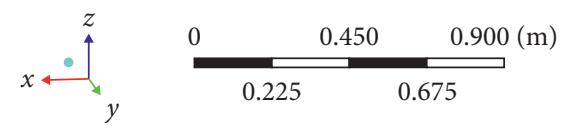

(a)

Velocity

$$
\text { v09 m }
$$

$$
\begin{array}{r}
1.000 e-003 \\
9.000 e-004 \\
8.000 e-004 \\
7.000 e-004 \\
6.000 e-004 \\
5.000 e-004 \\
4.000 e-004 \\
3.000 e-004 \\
2.000 e-004 \\
1.000 e-004 \\
0.000 e+000 \\
{\left[\mathrm{~m} \mathrm{~s}^{-1}\right]}
\end{array}
$$
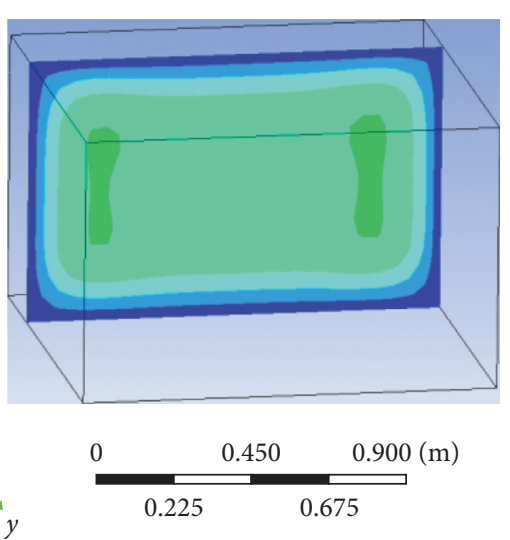

(c)

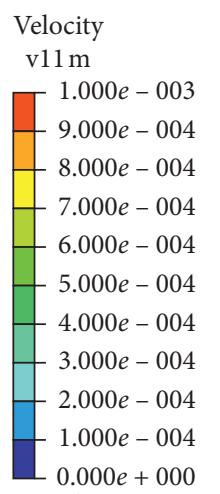
$\left[\mathrm{m} \mathrm{s}^{-1}\right.$ ]

$$
x \stackrel{\sim}{z} y
$$

0

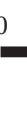

(e)
Velocity

$\mathrm{v} 06 \mathrm{~m}$
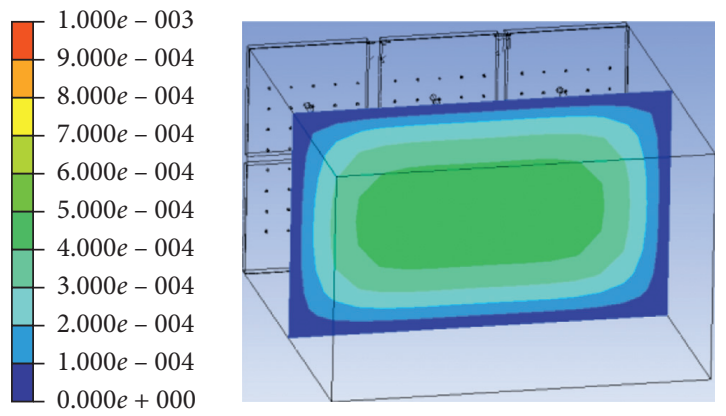

$\left[\mathrm{m} \mathrm{s}^{-1}\right.$ ]<smiles>[Y]C([Y])[14CH3]</smiles>

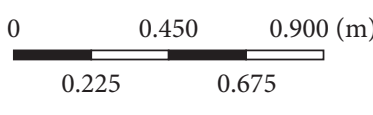

(b)

\section{Velocity \\ $\mathrm{v} 09 \mathrm{~m}$}
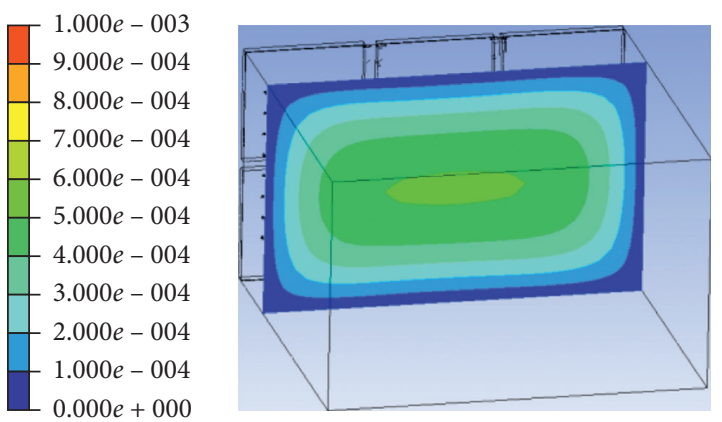

$\left[\mathrm{m} \mathrm{s}^{-1}\right]$
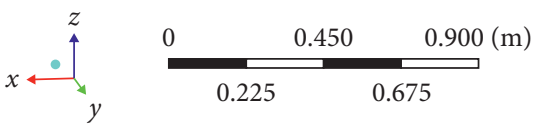

(d)

Velocity

v11 m
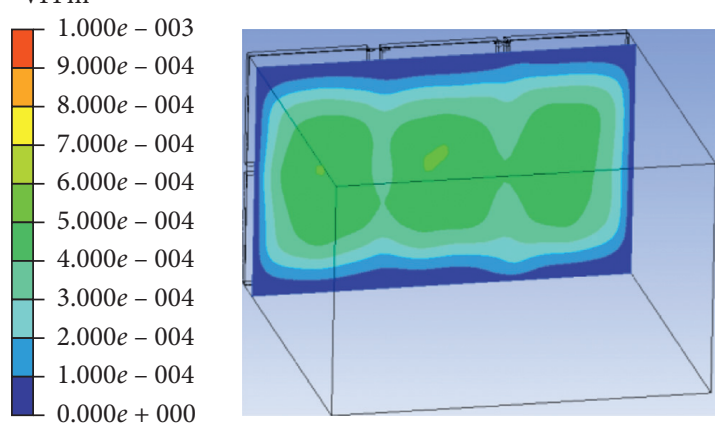

[ $\mathrm{m} \mathrm{s}^{-1}$ ]<smiles>[Y]C([Y])C</smiles>

$\frac{0.450 \quad 0.900(\mathrm{~m})}{0.225}$

(f)

Figure 5: Continued. 


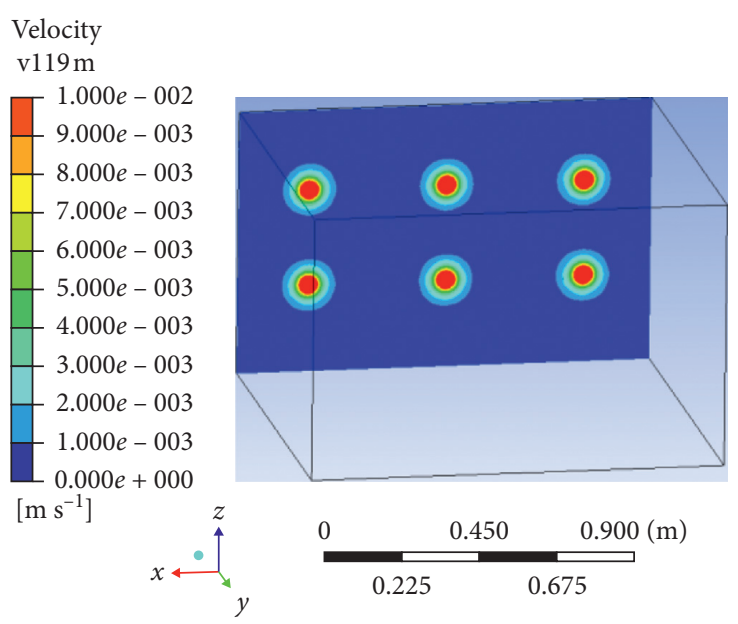

(g)

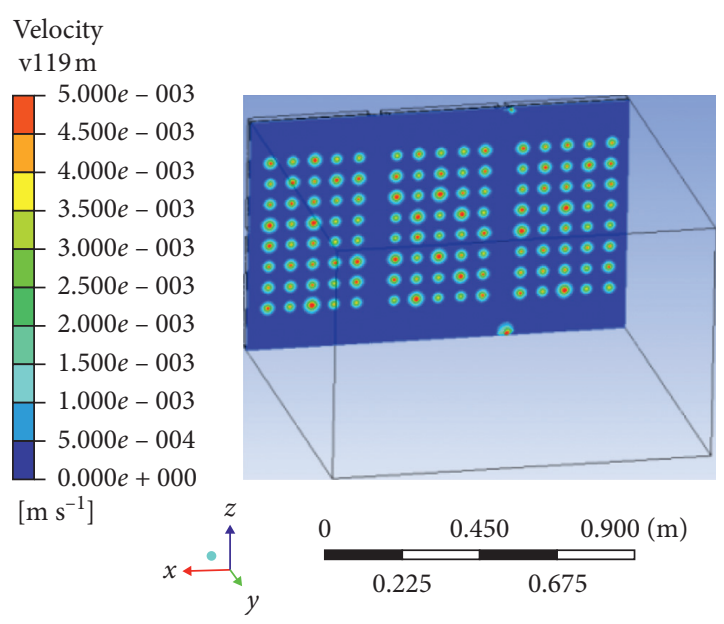

(h)

Figure 5: Comparison of porous plate effects: (a) without a porous plate, the hydraulic path length is $0.60 \mathrm{~m}$; (b) with a porous plate, the hydraulic path length is $0.60 \mathrm{~m}$; (c) without a porous plate, the hydraulic path length is $0.90 \mathrm{~m}$; (d) with a porous plate, the hydraulic path length is $0.90 \mathrm{~m}$; (e) without a porous plate, the hydraulic path length is $1.10 \mathrm{~m}$; (f) with a porous plate, the hydraulic path length is $1.10 \mathrm{~m}$; (g) without a porous plate, the hydraulic path length is $1.19 \mathrm{~m}$; (h) with a porous plate, the hydraulic path length is $1.19 \mathrm{~m}$.

An ordinary C-grade bolt was selected, and the tensile strength was $f_{t}^{b}=170 \mathrm{~N} / \mathrm{mm}^{2}$.

The sum of the minimum areas for all bolts requires the following:

$$
A=\frac{F_{\mathrm{a}}}{f_{t}^{\mathrm{b}}}=424 \mathrm{~mm}^{2}
$$

If bolts with a diameter of $8 \mathrm{~mm}$ are selected, the minimum required number of bolts is as follows:

$$
p=\frac{A}{A_{\mathrm{e}}}=12
$$

Therefore, the minimum number of bolts to be placed is 12.

3.3.2. Bolt Hole Layout and Water Sealing Design. The water sealing for the lower box body was completed by welding, and the water sealing design between the upper cover plate and lower box body was carried out in the following manner: a $3 \mathrm{~mm}$ thick iron sheet was pasted on the frame beam, and a water sealing silica gel strip was pasted on the inner side of the model box body. When the upper cover plate was spliced with the lower box, the silica gel strip with a smaller elastic modulus was deformed by extrusion. Due to the obstruction of the iron sheet, the silica gel strip deformed to the inner side of the box. The design goal of water sealing between the upper cover plate and lower box can be achieved through the silica gel strip deformation.

Three points should be noted in the bolt hole arrangement as follows:

(1) The bolt hole spacing should be greater than 10 times of the diameter of the bolt hole in order to reduce the impact of the bolt hole on the bearing capacity of the frame beam.

(2) The distance between bolt holes should not be too large because when the upper cover plate is spliced with the lower box, the silica gel strip would be extruded to deform and reach the water sealing target. If the spacing is too large, the local silica gel strip will not be effectively squeezed. Hence, the water sealing effect cannot be achieved.

(3) The number of bolt holes should meet the requirements of bearing capacity.

Based on the above, the bolt hole layout was finally determined, as shown in Figure 9.

\section{Application Examples}

After the design was completed, the drawings were handed over to the coprocessing plant for processing. The physical diagram of the seepage-freezing model test box after processing was completed, as shown in Figure 10.

The water sealing performance of the model box was checked by applying water pressure. First, the water outlet valve was closed, the water inlet valve was opened, and the water pump pressure was adjusted until the water inlet pressure gauge showed a pressure of $0.05 \mathrm{MPa}$. Then, the water inlet valve was closed. After one hour, it was checked whether there was water leakage around the box. If there was no water leakage, the box meets the requirements. After the test, there was no water leakage phenomenon after a water pressure of $0.05 \mathrm{MPa}$ was applied. This proves that the test box can meet the requirements of test pressure and water sealing performance. 


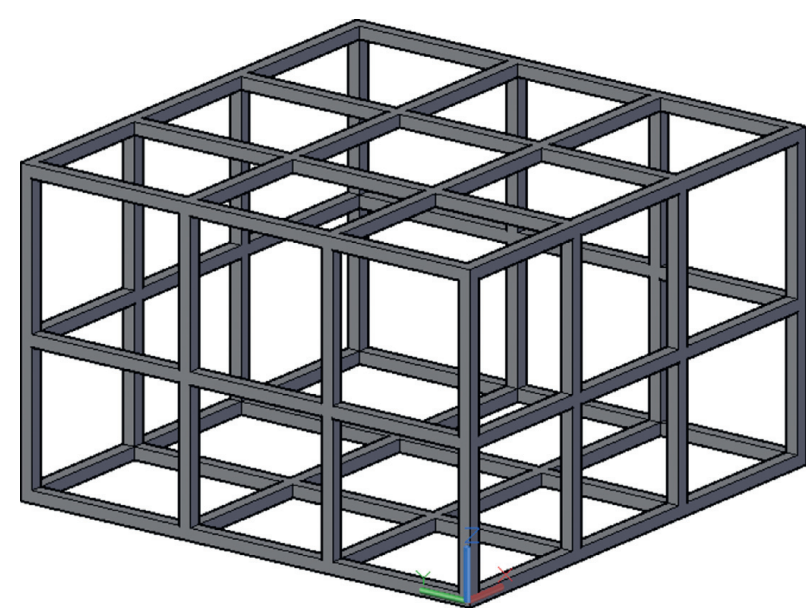

Figure 6: Schematic diagram for the frame.

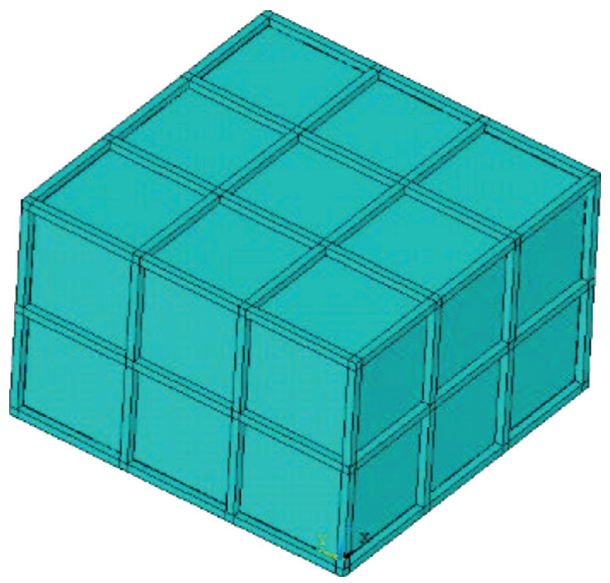

FIGURE 7: Structural analysis model.
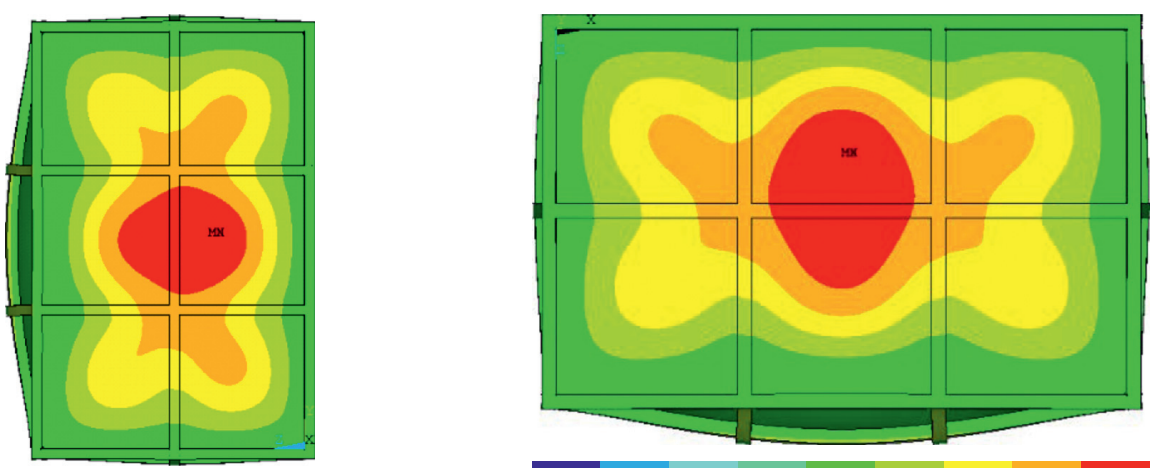

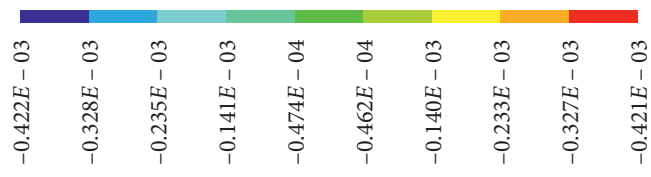

(a)

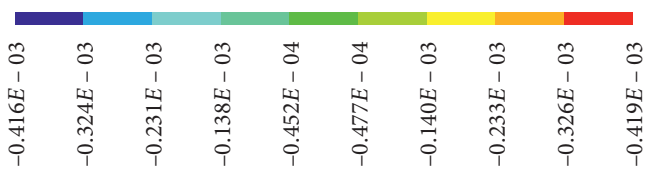

(b)

Figure 8: Continued. 


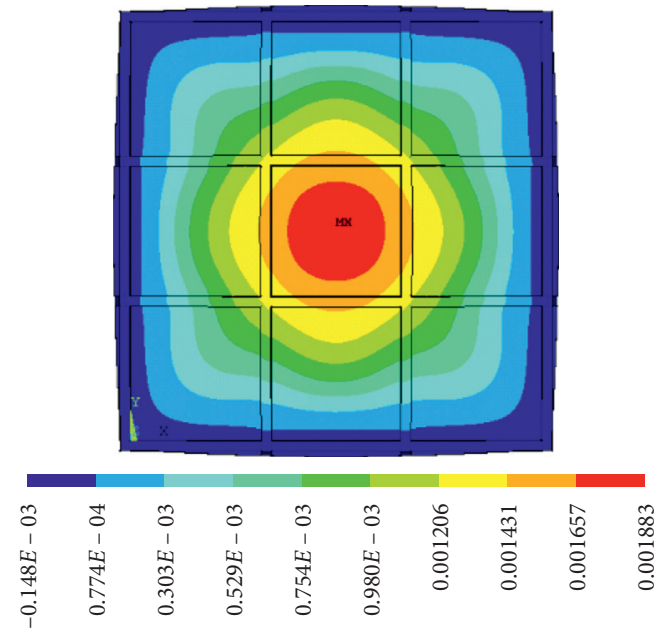

(c)

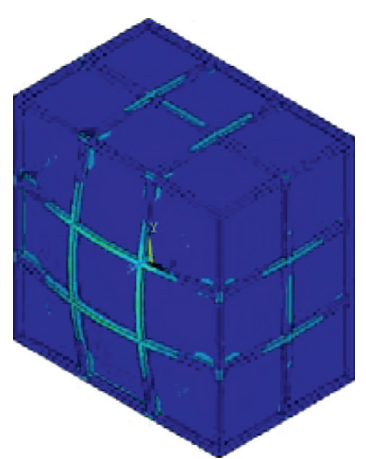

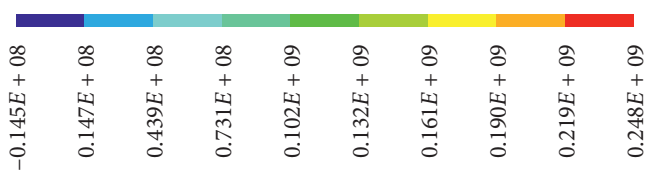

(d)

Figure 8: Distribution of (a) the displacement in the (x) direction; (b) the displacement in the (y) direction; (c) the displacement in the (z) direction; (d) stress of the model box.

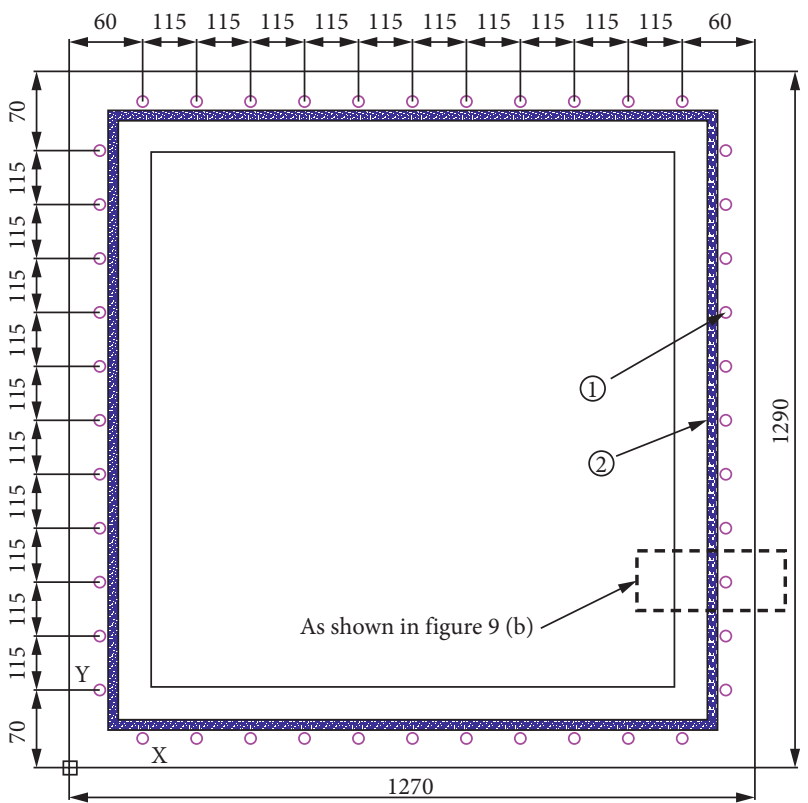

(a)

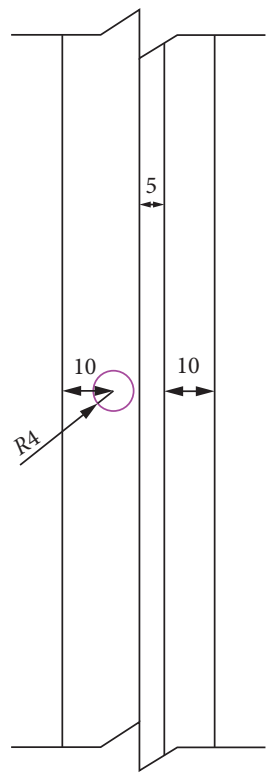

(b)

FIgURE 9: (a) Bolt hole layout. (b) Bolt hole layout details.

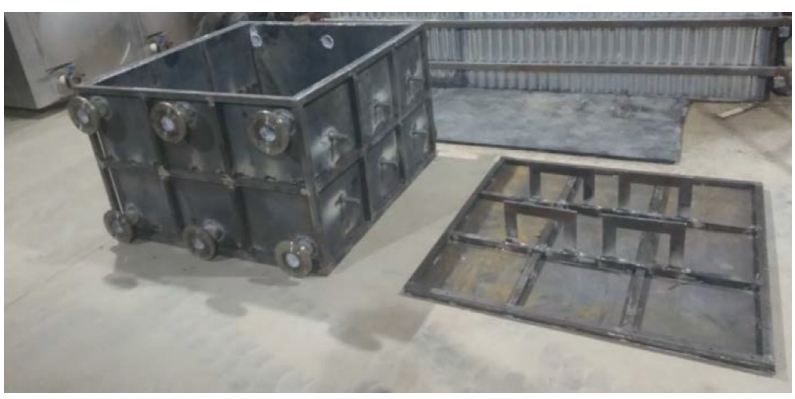

Figure 10: Physical drawing of box. 


\section{Conclusion}

The present study elaborates the design idea and process of a seepage-freezing model test box.

First, the design requirements and design indexes of the model box were proposed by theoretical calculation. Then, using flow field analysis, we determined whether the permeable plate has the effect of restraining the flow from converging to the orifice. Next, the numerical model of the structural analysis was established to design the load-bearing box, which can meet the structural design requirements. Finally, through the reasonable arrangement of bolts, iron sheets, and water sealing silica gel strips, the water sealing goal between the upper cover plate and the lower box was achieved. The main conclusions were as follows:

(1) Using theoretical analysis and calculation and based on safety considerations, the model box was designed as a pressure vessel. Then, $0.05 \mathrm{MPa}$ was taken as the pressure design index for the model box and $2.4 \mathrm{~mm}$ was taken as the maximum allowable deformation.

(2) The longer the hydraulic path length, the phenomenon of water flow convergence to the orifice was more significant and greater the difference between the maximum velocity of the model box with or without a permeable plate. This verifies that the permeable plate affects the water flow dispersal and stimulates the laminar flow.

(3) The composite structure form of "panel + frame beam" was adopted to bear the load. When the panel thickness of the seepage-freezing model test box was $5 \mathrm{~mm}$ and the cross section size of the frame beam was $3030 \mathrm{~mm}$, the maximum displacement of the model box in the $x, y$, and $z$ directions was less than $2.40 \mathrm{~mm}$ after the bearing pressure of $0.05 \mathrm{MPa}$. The maximum stress of the box was approximately $248 \mathrm{MPa}$, which was less than $250 \mathrm{MPa}$. Hence, the box can meet the requirements of strength and deformation.

(4) Through calculation and analysis, the minimum number of arranged bolts was 12 . The water sealing target between the upper cover plate and lower box body was achieved through the reasonable arrangement of bolts, iron sheets, and sealing strips.

Finally, using the actual test of the processed box, it was proven that the model test box could fully meet the test requirements. These research results can provide a reference for the design and development of other seepage-freezing model test boxes.

\section{Data Availability}

The data used to support the findings of this study are included within the article.

\section{Conflicts of Interest}

The authors declare that they have no conflicts of interest.

\section{Acknowledgments}

The research described in this paper was financially supported by the Beijing Science and Technology Commission (Z161100001116088).

\section{References}

[1] J. Lin, H. Cheng, H.-B. Cai, B. Tang, and G.-Y. Cao, "Effect of seepage velocity on formation of shaft frozen wall in loose aquifer," Advances in Materials Science and Engineering, vol. 2018, no. 2, 11 pages, Article ID 2307157, 2018.

[2] Z. Liu, Y. Sun, B. Wang, and Q. Li, "Experimental study of artificial ground freezing by natural cold gas injection," $A p$ plied Sciences, vol. 10, no. 17, Article ID 6055, 2020.

[3] Y. Qi, J. Zhang, H. Yang, and Y. Song, "Application of artificial ground freezing technology in modern urban underground engineering," Advances in Materials Science and Engineering, vol. 2020, no. 4, 12 pages, Article ID 1619721, 2020.

[4] M. Vitel, A. Rouabhi, M. Tijani, and F. Guérin, "Modeling heat transfer between a freeze pipe and the surrounding ground during artificial ground freezing activities," Computers and Geotechnics, vol. 63, pp. 99-111, 2015.

[5] M. Vasilyeva, S. Stepanov, D. Spiridonov, and V. Vasiliy, "Multiscale finite element method for heat transfer problem during artificial ground freezing-sciencedirect," Journal of Computational and Applied Mathematics, vol. 371, Article ID 112605, 2020.

[6] X. M. Zhou, M. S. Wang, and X. Z. Zhang, "Model test research on the formation of freezing wall in seepage ground," Journal of China Coal Society, vol. 30, no. 2, pp. 196-201, 2005.

[7] R. A. Sudisman, M. Osada, and T. Yamabe, "Experimental investigation on effects of water flow to freezing sand around vertically buried freezing pipe," Journal of Cold Regions Engineering, vol. 33, no. 3, pp. 04019004.1-04019004.12, 2019.

[8] A. Mauro, G. Normino, F. Cavuoto, P. Marotta, and N. Massarotti, "Modeling artificial ground freezing for construction of two tunnels of a metro station in napoli (Italy)," Energies, vol. 13, no. 5, p. 1272, 2020.

[9] P. Yang and A. I. R. Pi, "Study on the effects of large groundwater flow velocity on the formation of frozen wall," Chinese Journal of Geotechnical Engineering, vol. 23, no. 2, pp. 167-171, 2001.

[10] H. Tounsi, A. Rouabhi, and E. Jahangir, "Thermo-hydromechanical modeling of artificial ground freezing taking into account the salinity of the saturating fluid," Computers and Geotechnics, vol. 119, Article ID 103382, 2020.

[11] Y.-M. Lai, Z. Wu, Y. Zhu, and L. Zhu, "Nonlinear analysis for the coupled problem of temperature and seepage fields in cold regions tunnels," Cold Regions Science and Technology, vol. 29, no. 1, pp. 89-96, 1999.

[12] E. Pimentel, A. Sres, and G. Anagnostou, "Large-scale laboratory tests on artificial ground freezing under seepage-flow conditions," Géotechnique, vol. 62, no. 3, pp. 227-241, 2012.

[13] F. Z. Li and M. P. Xia, "Study on analytical solution of temperature field of artificial frozen soil by exponent-integral 
function," Journal of Southeast University (Natural Science Edition), vol. 34, no. 4, pp. 469-473, 2004.

[14] X. D. Hu, "Average temperature model of double-row-pipe frozen soil wall by equivalent trapezoid method, AIP conference proceedings," AIP, vol. 1233, no. 1, pp. 1333-1338, 2010.

[15] X. D. Hu and T. X. He, "Equivalent-trapezoid method of average temperature calculation for multi-row-pipe straight frozen soil wall," Journal of China Coal Society, vol. 34, no. 11, pp. 1465-1469, 2009.

[16] R. Shan, W. Liu, G. Chai, and S. Xiao, "Experimental study on influencing factors of characteristic index of local horizontal frozen body of double-row pipe under seepage," Advances in Materials Science and Engineering, vol. 2020, no. 11, 11 pages, Article ID 8267692, 2020.

[17] B. Wang, C.-X. Rong, J. Lin, H. Cheng, and H.-B. Cai, "Study on the formation law of the freezing temperature field of freezing shaft sinking under the action of large-flow-rate groundwater," Advances in Materials Science and Engineering, vol. 2019, Article ID 1670820, 20 pages, 2019.

[18] Y. S. Kim, J.-M. Kang, J. Lee, S.-S. Hong, and K.-J. Kim, "Finite element modeling and analysis for artificial ground freezing in egress shafts," Ksce Journal of Civil Engineering, vol. 16, no. 6, pp. 925-932, 2012.

[19] E. Pimentel, S. Papakonstantinou, and G. Anagnostou, "Numerical interpretation of temperature distributions from three ground freezing applications in urban tunnelling," Tunnelling and Underground Space Technology, vol. 28, pp. 57-69, 2012.

[20] X. X. Mao, Dike Engineering Manual, China Water \& Power Press, Beijing, China, 2009. 